\title{
Biochemical determinants of thrombin generation in a general population with arterial and venous disease background
}

\author{
Pauline C.S. van Paridon \\ Maastricht University Medical Centre
}

\section{Marina Panova-Noeva}

University Medical Center of the Johannes Gutenberg University Mainz

\section{Rene van Oerle}

Maastricht University Medical Centre

\section{Andreas Schulz}

University Medical Center of the Johannes Gutenberg University Mainz

Jürgen H. Prochaska

University Medical Center of the Johannes Gutenberg University Mainz

\section{Natalie Arnold}

University Medical Center of the Johannes Gutenberg University Mainz

\section{Irene Schmidtmann}

University Medical Center of the Johannes Gutenberg University Mainz

\section{Manfred Beutel}

University Medical Center of the Johannes Gutenberg University Mainz

\section{Norbert Pfeiffer}

University Medical Center of the Johannes Gutenberg University Mainz

\section{Thomas Münzel}

University Medical Center of the Johannes Gutenberg University Mainz

\section{Karl J. Lackner}

University Medical Center of the Johannes Gutenberg University Mainz

\section{Hugo ten Cate}

Maastricht University Medical Centre

\section{Philipp S. Wild}

University Medical Center of the Johannes Gutenberg University Mainz

Henri M.H. Spronk ( $\sim$ henri.spronk@maastrichtuniversity.nl )

Maastricht University Medical Centre

\section{Research Article}

Keywords: Coagulation factors, thrombin generation, arterial thrombosis, venous thrombosis

Posted Date: February 9th, 2022

DOI: https://doi.org/10.21203/rs.3.rs-1303017/v1

License: (c) (i) This work is licensed under a Creative Commons Attribution 4.0 International License. Read Full License 


\section{Abstract}

Background: The current study aims to identify the biochemical determinants of plasma thrombin generation in a large population-based study by comparing individuals with a history of arterial or venous thrombosis to cardiovascular healthy individuals.

Methods: This study comprised 502 individuals with a history of arterial disease, 195 with history of venous thrombosis and 1402 cardiovascular healthy individuals (reference sample) from the population-based Gutenberg Health Study (GHS). Calibrated Automated Thrombography was assessed and coagulation factors were measured by means of BCS XP Systems. To assess the biochemical determinants of TG variables, a multiple linear regression analysis, adjusted for age, sex and antithrombotic therapy, was conducted.

Results: The lag time was mainly positively associated with the natural coagulant and anti-coagulant factors in the reference sample, i.e. higher factors result in a longer lag time. The same determinants were negative for individuals with a history of arterial or venous thrombosis, with a 10 times higher effect size. ETP was predominantly positively determined by factor II, VIII, X and IX in all subsamples. However, the effect sizes of the reported associations were 4 times higher for the arterial and venous subsamples in comparison to the reference sample.

Conclusion: This large-scale analysis demonstrated a stronger effect of the coagulant and natural anti-coagulant factors on the thrombin potential in individuals with a history of arterial or venous thrombosis as compared to healthy individuals, which implicates sustained alterations in the plasma coagulome in subjects with a history of thrombotic vascular disease, despite intake of antithrombotic therapy.

\section{Introduction}

Thrombin generation (TG) is established as an important research tool for exploring the plasma "coagulome" in relation to clinical risks for bleeding or thromboembolism. For a bleeding tendency, like hemophilia subjects lacking factor VIII or IX, reduced peak height and endogenous thrombin potential (ETP) of the TG curve have been observed, supporting a state of hypocoagulability. ${ }^{1-5}$ Correction of such factor deficiency normalized the TG profile. ${ }^{6}$ In thrombosis research, the reported findings on TG are conflicting, e.g. whereas an increased thrombin potential is frequently reported in venous thrombosis, for subjects with arterial thrombosis data are quite inconsistent. ${ }^{7-10}$ While some studies show positive associations of increased peak height and/or ETP to outcomes like ischemic stroke, other studies show reverse associations of increased lag time and/or lower peak height levels in patients that suffered a myocardial infarction or stroke. ${ }^{11,12}$ The reasons for these discrepancies are not fully understood but might include variations in coagulation factor concentrations, release of tissue factor pathway inhibitor from the endothelium as well as effects of specific medication. Solid evidence based on a comprehensive set of different data is still missing. ${ }^{13}$

Venous thromboembolism (VTE) and arterial thrombotic diseases share several risk factors and several studies have shown that the risk of arterial thrombosis is increased in those that suffered a first VTE and vice versa. ${ }^{14}$ Therefore, one would expect that also the plasma coagulome, assessed by the TG assay, would reflect certain similarities between subjects with VTE or arterial thrombosis. ${ }^{15}$ However, given the observed discrepant associations with TG data, different profiles between venous and arterial thrombotic disease may also be present.

In order to address these issues, we carried out the present study to identify the biochemical determinants (coagulation factors and natural anti-coagulants) of the TG parameters in individuals with a history of either an arterial cardiovascular disease or venous thrombotic disease compared to cardiovascular healthy group within the population-based Gutenberg Health Study. 


\section{Methods}

Research design

The Gutenberg Health Study (GHS) is a prospective, observational, single center cohort study, designed for populationbased health research, in the Rhine-Main region in Germany. With a total of 15,010 individuals between 35 and 74 years enrolled at the baseline examination, the GHS aims to assess the consequences of diseases and environmental factors in addition to the inherited predisposition on the development and progression of asymptomatic and symptomatic disease. During the baseline visit, every participant underwent a comprehensive, standardized 5-hour clinical examination program, as reported elsewhere. ${ }^{16,17}$ In addition to the clinical assessment, a large biobank has been established for future biochemical and genetic analyses. Details of the study protocol and the further purposes of the study are discussed elsewhere. ${ }^{18}$

\section{Study sample}

The overall study sample consisted of the first 5000 subjects enrolled into the GHS between April 2007 and October 2008 . After excluding subjects without biomaterial available or without complete TG assessment (one or several TG parameters were missing), 4843 individuals were successfully included in the present analysis.

The reference group was defined as apparently cardiovascular healthy subjects without history of cardiovascular diseases (myocardial infarction [MI], congestive heart failure [CHF], coronary artery disease [CAD], peripheral artery disease [PAD], venous thromboembolism [VTE], atrial fibrillation [AF]), presence of cardiovascular risk factors (CVRF; obesity, dyslipidemia, arterial hypertension, diabetes mellitus) and included 1402 individuals. Individuals with a self-reported history of inherited coagulation abnormalities were excluded from the reference sample. The arterial subsample was defined as individuals with a history of MI, CAD, stroke or PAD and included 502 individuals. The venous subsample was defined as individuals with a history of deep venous thrombosis (DVT) or pulmonary embolism (PE) and included 195 individuals.

\section{Definition of classical cardiovascular risk factors}

Diabetes mellitus and dyslipidemia were defined as individuals with a definite diagnosis of by a physician. Additional definition of diabetes was a blood glucose level of $\geq 126 \mathrm{mg} / \mathrm{dl}$ in the baseline examination after an overnight fast of at least 8 hours or a blood glucose level of $\geq 200 \mathrm{mg} / \mathrm{dl}$ in the baseline examination after a fasting period $<8$ hours.

Dyslipidemia was additionally defined as a LDL/HDL-ratio of $>3.5$. Hypertension was diagnosed, if antihypertensive drugs are taken, or a mean systolic blood pressure of $\geq 140 \mathrm{mmHg}$ or a mean diastolic blood pressure of $\geq 90 \mathrm{mmHg}$ (in the $2 \mathrm{nd}$ and 3rd standardized measurement after 8 and 11 minutes of rest). Smoking was classified into non-smokers (never smokers and former smokers) and smokers (occasional smoker, i.e. $<1$ cigarette/day, and smoker, i.e. $\geq 1$ cigarette/day). Obesity defined as a body-mass index $\geq 30 \mathrm{~kg} / \mathrm{m}^{2}$. Self-reported coronary artery disease (CAD), myocardial infarction (MI), heart failure (HF), stroke, deep vein thrombosis (DVT), pulmonary embolism (PE) and peripheral arterial disease (PAD) indicated personal history of cardiovascular disease. A positive family history was defined as history of myocardial infarction or stroke in a female first-degree relative $\leq 65$ years or a male first-degree relative $\leq 60$ years.

\section{Categorization of medication}

Medications were classified according to the Anatomical Therapeutic Chemical (ATC) classification system. The following medication groups were selected for analysis: anticoagulant agents (B01), sex hormones and modulators of the genital system (G03). For the use of oral contraceptives and/or hormone replacement therapy, both ATC-code and self-reported information were used. 
Venous blood sampling was performed according to standard operating procedures and the blood was collected in trisodium citrate $(0.109 \mathrm{M}, 1: 9 \mathrm{vol}: \mathrm{vol})$ monovette plastic tubes, while the subject was in fasting state (i.e. overnight fast, if subject was examined before 12 a.m. and 5 hour fast, if subject was examined after 12 a.m.). Platelet poor plasma (PPP) was prepared by one-step centrifugation at 2,000 $\mathrm{x} g$ at room temperature for 10 minutes. After preparation the PPP was aliquoted and immediately stored at $-80^{\circ} \mathrm{C}$ in the Biobank of the GHS study center.

The TG was assessed in the Laboratory for Clinical Thrombosis and Hemostasis, Maastricht University, the Netherlands, by the Calibrated Automated Thrombogram (CAT) assay (Thrombinoscope BV, Maastricht, The Netherlands), according to the recommendations. ${ }^{19,20}$ The TG was triggered by PPP Reagent Low (Stago) in freshly thawed PPP. The CAT method employs a low affinity fluorogenic substrate for thrombin (Z-Gly-Gly-Arg-AMC) to continuously monitor thrombin activity in clotting plasma. TG measurements were calibrated against the fluorescence curve obtained in a sample from the same plasma $(80 \mu \mathrm{L})$, supplemented with a fixed amount of thrombin-alfa 2-macroglobulin complex $(20 \mu \mathrm{L}$ of Thrombin Calibrator; Thrombinoscope BV, Maastricht, The Netherlands) and $20 \mu \mathrm{L}$ of the fluorogenic substrate and calcium chloride mixture. TG parameters were derived from the TG curve and include lag time (time to minimum thrombin formed [min]), peak height (the maximum amount of thrombin formed [nM]) and endogenous thrombin potential (ETP or area under the curve [nM.min]).

Coagulation factors were measured by means of BCS XP Systems in the Biomolecular laboratory at the Department of Epidemiology, University Medical Center Mainz, Germany. The coagulation factors II, V, VII, VIII, IX, X, XI, XII were determined using the clotting-based coagulation methodology, protein $\mathrm{C}$ and antithrombin by the chromogenic assay and von Willebrand factor (VWF) and protein S by using immunological-based assay.

Total TFPI activity was assessed in PPP by the Actichrome TFPI activity assay (American Diagnostica, Stamford, CT, USA) in the Laboratory for Clinical Thrombosis and Hemostasis, Maastricht University, the Netherlands.

\section{Data management and statistical analysis}

A central data management unit conducted quality control on all data in this study. Statistical analysis was performed with software program R, version 3.3.1 (http://www.R-project.org).

Data on coagulation factors and inhibitors are presented as mean (standard deviation) in case of normal distribution.

Multiple linear regressions were used to assess the associations between biochemical variables and TG parameters in the reference sample as well as in the arterial and venous samples. The analyses were adjusted for age, sex and additionally for hormones (oral contraceptives and hormone replacement therapy $=G 03$ ) and anti-coagulant agents $(B 01 A A, B 01 A B$, $\mathrm{B} 01 \mathrm{AE}, \mathrm{B} 01 \mathrm{AF}, \mathrm{B} 01 \mathrm{AX}$ ) as these may affect the thrombin potential. Due to a skewed distribution, lag time, as a dependent variable, was log-transformed prior to the analysis. Estimated beta regression coefficients, presented with corresponding 95\% confidence interval $(\mathrm{Cl})$, were calculated as per standard deviation to compare the effects of different coagulationrelated factors on TG parameters. Due to its explorative nature, a p-value threshold was not defined. However, to account for multiple testing, a Bonferroni corrected p-value (0.00036) was set for the results on the multiple linear regression analyses.

\section{Results}

\section{Baseline characteristics of the study sample}

Baseline characteristics of the reference, arterial and venous subsamples are shown in Table 1. The majority of the individuals in the arterial subsample were males (63.3\%), whereas there was a preponderance of females in the reference subsample (60.5\%) and the venous subsample (63.6\%). The mean age in the reference subsample was 49.3 years and the 
mean age of the study population in the arterial and venous subsample was 63.8 years and 61.3 years, respectively. In both the arterial and venous subsample, hypertension (arterial subsample: $72.5 \%$, venous subsample: $59.0 \%$ ) was the most prevalent traditional CVRF, followed by family history of $\mathrm{Ml}$ /stroke (arterial subsample: $43.6 \%$, venous subsample: $43.6 \%$ ). Of the cardiovascular diseases, CAD was the most prevalent with $46.5 \%$ of the study subjects in the arterial subsample. In the venous subsample, $99.0 \%$ of the individuals had a history of DVT and $5.7 \%$ of the individuals in this subsample had a history of PE. Of the arterial vascular diseases, PAD was predominant with $26.6 \%$ of the study subjects in the venous subsample. a medication was most common in the arterial subsample (61.0\%), followed by the venous subsample (35.4\%) and the reference subsample (1.8\%). While individuals from the reference subsample were most often taking oral contraceptive therapy (12.5\%), individuals in the arterial subsample were most often using hormonal replacement therapy (11.3\%).

\section{Levels of coagulation factors and inhibitors}

Levels of coagulation factors and inhibitors in the reference, arterial and venous subsample are shown in Table 2. Most notably, the lag time was significantly prolonged in individuals with a history of arterial vascular disease or venous thrombosis in comparison to the cardiovascular healthy individuals. In addition, the ETP from the arterial subsample was lower compared to the reference sample. The activity level of factors II, $X$ and antithrombin were lower in the arterial and venous subsamples compared to the reference subsample. Differently, activity levels of factors VIII and XI, vWF activity and fibrinogen concentration were higher in both arterial and venous subsamples compared to control subsample. The individuals from the arterial sample compared to the control subjects showed additionally higher activity levels of factor IX and Protein S and slightly lower activity of factor XII.

\section{Determinants of thrombin generation}

The multivariate analysis of the determinants of the TG assay in the reference, arterial and venous subsamples is presented in Table 3. Presented in table 3 are beta per standard deviation SD, meaning that one SD change of the predictor (coagulation factors) leads to beta change in dependent variable (TG parameter). The lag time in the arterial and venous subsample was strongly and negatively associated with coagulation factors II, V and VII and with the natural anticoagulants protein S, antithrombin and TFPI activity. Fibrinogen was negatively associated with the lag time in the arterial subsample and positively associated in the venous subsample. Differently, factor XII was positively associated with the lag time in the arterial subsample and negatively associated in the venous subsample. In general, the effect size of the reported biochemical determinants was 10 times higher for the arterial and venous subsamples compared to the reference sample (e.g. factor II, beta estimate median: arterial: $-0,18$ vs venous -0.23 vs reference 0.017 ). In addition, the direction of the associations for the reference subsample was positive for all reported variables, except for factor VII that was negatively associated.

The ETP was strongly positively determined by factor II, VIII, X and IX in the reference sample as well as the arterial and venous subsample.(Table 3 ) In addition, antithrombin was a negative determinant for the ETP in the reference sample, though no association was observed for antithrombin in the arterial and venous subsamples. VWF was a negative determinant for the ETP in both the arterial and venous subsample, whereas VWF was positively associated with the ETP in the reference sample. Moreover, the effect size of the reported biochemical determinants was nearly 4 times higher for the arterial and venous subsamples in comparison to the reference sample (e.g. factor VIII, beta estimate median: arterial 184 vs venous 217 vs reference 55.6 ).

There was a positive association between factor VIII, IX, II, X and the peak height in the reference sample, arterial and venous subsample. (Table 3 ) Protein $S$ was a negative determinant of the peak height in the reference sample, whereas it was positively associated with the peak height in the arterial and venous subsample. In addition, factor IX was a negative determinant for the peak height in the reference sample, though no association was found in the arterial and venous subsample. In general, the effect sizes for the reported biochemical determinants of the peak height were similar in all 
subsamples, with the exception of factor VII that had lesser effect in the arterial subsample compared to the reference sample and venous subsample (beta estimate: arterial: 10.4 vs venous 24.4 reference 17.6 ).

\section{Discussion}

This is the first large scale population-based study that has explored the biochemical determinants of the TG parameters in individuals with a history of arterial vascular disease or venous thrombotic disease, as compared to cardiovascular healthy individuals. The main findings from our study show important distinct differences for the biochemical determinants between cardiovascular healthy individuals and those with a background of an arterial or venous disease. Whereas lag time was mainly negatively associated with the procoagulant and anti-coagulant factors in the plasma, meaning higher factor levels result in a shorter lag time, the same associations were positive for the healthy individuals. Furthermore, the effect size for the biochemical parameters determining the lag time was about 10 times higher for the arterial and venous disease than for the reference subsample.

Dielis et al. previously investigated the coagulation factors as determinants of the TG parameters at 1 pM TF (comparable to the applied PPP Reagent Low) and 13.6 pM TF in the absence or presence of thrombomodulin or in the absence or presence of activated protein $\mathrm{C}$ in a sample of healthy adults. ${ }^{21} \mathrm{TFPI}$ activity, protein $\mathrm{S}$ and fibrinogen were the strongest positive determinants of the lag time. Similarly, the results of the present study showed that TFPI activity, protein S and fibrinogen are strong positive determinants of the lag time in the control individuals. Fibrinogen was also positively associated with the lag time from the venous disease subsample. A possible explanation for the paradoxical association between fibrinogen and lag time may be the anti-coagulant properties of fibrinogen by inhibiting the binding with thrombin directly as well as through accelerating the activation of plasminogen into plasmin by tissue plasminogen activator. ${ }^{22}$ Interestingly, for the arterial disease individuals, higher fibrinogen concentration was associated with shorter lag time. These contrasting results raise the possibility of differential effects of fibrinogen on the initiation phase of the TG process in diseases affecting different vascular beds. Factor VII was the unique coagulation factor that shared the same direction of association with the lag time for control subjects and disease individuals. Factor VII is well known to play an important role in the initiation phase of the coagulation cascade by formation of the factor VIla/TF complex that promotes the generation of the prothrombinase complex (factor Xa/factor Va) and ultimately leads to TG amplification. ${ }^{23}$ Higher factor VII activity level and shorter lag time, shared by both control and disease individuals, confirms the role of factor VII in the ambient coagulation cascade reaction.

Furthermore, Dielis and colleagues reported fibrinogen and factor XII as positive determinants for the ETP, which we confirmed in the present study. ${ }^{21}$ As expected and as previously reported, antithrombin, a potent anti-coagulant, was negatively associated with the ETP. In general, the present analysis demonstrated that the direction of associations with coagulation factors and ETP were similar in the reference sample, arterial and venous subsample.

The analysis of the levels of natural coagulation and anti-coagulant factors showed that factor II, VIII, X and XI were significantly increased in the subjects with an arterial or venous disease background in comparison to the healthy individuals, which is in accordance with previous reports. ${ }^{9,24-29}$ This finding illustrates a "hypercoagulable" state in these subjects and may explain the fourfold increased effect size of the associations with the reported coagulation factors and the ETP in arterial and venous subsample compared to the reference sample. This is further supported by evidence from previous TG assay studies demonstrating its potential to expose hypercoagulability in plasma from patients with arterial and venous thrombosis. ${ }^{30}$

In contrast to the reference sample, protein S, a natural anti-coagulant, was a positive determinant for the peak height in individuals with a history of arterial or venous thrombotic disease. Our analysis confirms increased levels of coagulation factors in patients with an arterial or venous thrombotic disease background, which could potentially result in excessive activation of the activated protein $\mathrm{C}$ pathway to which protein $\mathrm{S}$ is a supporting cofactor. Therefore, as demonstrated by 
the analysis from the arterial subsample, levels of protein S may be elevated. However, the net effect of these pathological mechanism remains an increased thrombin generation which translates to the increased peak height. The effect sizes of the associations with the peak height were similar for healthy individuals and individuals with an arterial or venous thrombotic disease background.

Limitations to the study were: The history of arterial or venous disease was self-reported by the participants. There was no data available for analysis on the time from the initial diagnosis of the arterial and/or venous event to study enrolment. Therefore, we were not able to investigate if different duration of disease has different impact on the coagulation and TG profile.

However, this study has important strengths, including the standardized clinical investigation of the participants' present cardiovascular profile and the comprehensive laboratory investigation of coagulation and anti-coagulant factors.

\section{Conclusions}

This large-scale analysis of TG assay biochemical determinants shows that the individual coagulation factors more strongly affect TG parameters in individuals with a history of arterial or venous thrombosis as compared to cardiovascular healthy individuals. This illustrates the different effect size contribution of the coagulation factors to the hypercoagulable state of individuals at risk for a cardiovascular event and suggests that the coagulome might be tuned to a "hypersensitive" state increasing the risk for recurrence. Overall, the important finding of altered determinants of thrombin generation shows that in patients with a history of cardiovascular disease levels of coagulation factors should be considered. It also provides further rationale for the observed benefits of anti-coagulant therapy in patients with cardiovascular disease at risk of atherothrombosis.

\section{Declarations}

\section{Ethics approval and consent to participate}

The study has been conducted in accordance with the tenets of the revised Declaration of Helsinki. The study protocol was approved by the local ethics committee and by the local and federal data safety commissioners (Ref. No. 837.020.07 [5555]). Written informed consent was obtained from all participants for laboratory analyses, clinical examinations, sampling of biomaterial and use of data records for research purposes.

\section{Consent for publication}

Not applicable.

\section{Availability of data and materials}

The dataset used and/or analysed during the current study are available from the corresponding author on reasonable request.

\section{Conflict of interest}

H.M.H.S. and H.t.C. received funding for research from Bayer and Pfizer, outside the work presented in this paper. There were no diclosures to report for the remaining authors.

\section{Sources of funding}

The Gutenberg Health Study is funded through the government of Rhineland-Palatinate („Stiftung RheinlandPfalz für Innovation", contract AZ 961-386261/733), the research programs "Wissen schafft Zukunft" and "Center for Translational 
Vascular Biology (CTVB)" of the Johannes Gutenberg-University of Mainz, and its contract with Boehringer Ingelheim and PHILIPS Medical Systems, including unrestricted grants for the Gutenberg Health Study. H. ten Cate was a Fellow of the Gutenberg Research Foundation.

\section{Author contributions}

P.C.S. van Paridon performed research, analyzed and interpreted data, and wrote the paper; M. Panova-Noeva interpreted data and contributed to writing the paper; R. van Oerle performed research and contributed to writing the paper; A. Schulz performed the statistical analysis; N. Arnold and J.H. Prochaska contributed to discussion of the results and to critical review; I. Schmidtmann, M. Beutel and N. Pfeiffer performed research; T. Münzel, K.J. Lackner and H. ten Cate contributed to writing the paper and to critical review; P. Wild and H.M.H. Spronk designed and performed research, interpreted data and contributed to writing the paper.

\section{Acknowledgements}

We would like to express our gratitude to all participants and the staff who are involved in planning and conducting the GHS.

\section{References}

1. Dieri RA, Al Dieri R, Peyvandi F, Santagostino E, Giansily M, Mannucci PM, et al. The Thrombogram in Rare Inherited Coagulation Disorders: Its Relation to Clinical Bleeding [Internet]. Thrombosis and Haemostasis. 2002. page 576-82. Available from: http://dx.doi.org/10.1055/s-0037-1613258

2. Dieri RA, Al Dieri R, Wagenvoord R, Van Dedem GWK, Beguin S, Hemker HC. The inhibition of blood coagulation by heparins of different molecular weight is caused by a common functional motif-the C-domain [Internet]. Journal of Thrombosis and Haemostasis. 2003. page 907-14. Available from: http://dx.doi.org/10.1046/j.1538-7836.2003.00211.x

3. Hemker HC, Giesen P, AlDieri R, Regnault V, de Smed E, Wagenvoord R, et al. The calibrated automated thrombogram (CAT): a universal routine test for hyper- and hypocoagulability. Pathophysiol Haemost Thromb. 2002;32:249-53.

4. Eriksson U, Mattsson C, Wolzt M, Frison L, Fager G, Gustafsson D, et al. Inhibition of Thrombin Generation by the Oral Direct Thrombin Inhibitor Ximelagatran in Shed Blood from Healthy Male Subjects [Internet]. Thrombosis and Haemostasis. 2002. page 300-5. Available from: http://dx.doi.org/10.1055/s-0037-1612989

5. Hc H. Béguin s. Phenotyping the clotting system. Thromb Haemost. 2000;84:747-51.

6. Chelle P, Montmartin A, Piot M, Ardillon L, Wibaut B, Frotscher B, et al. Prediction of individual factor VIII or IX level for the correction of thrombin generation in haemophilic patients. Haemophilia. 2018;24:995-1001.

7. Dielis AJH, Spronk HMH, van Oerle R, Hamulyak K, Prins MH, ten Cate H, et al. Thrombin generation in patients after acute deep-vein thrombosis [Internet]. Thrombosis and Haemostasis. 2008. page 240-5. Available from: http://dx.doi.org/10.1160/th08-02-0099

8. Marchetti M, Castoldi E, Spronk HMH, van Oerle R, Balducci D, Barbui T, et al. Thrombin generation and activated protein $C$ resistance in patients with essential thrombocythemia and polycythemia vera. Blood. 2008;112:4061-8.

9. Loeffen R, van Oerle R, Leers MPG, Kragten JA, Crijns H, Spronk HMH, et al. Factor Xla and Thrombin Generation Are Elevated in Patients with Acute Coronary Syndrome and Predict Recurrent Cardiovascular Events [Internet]. PLOS ONE. 2016. page e0158355. Available from: http://dx.doi.org/10.1371/journal.pone.0158355 
10. Smid M, Dielis AWJH, Winkens M, Spronk HMH, van Oerle R, Hamulyák K, et al. Thrombin generation in patients with a first acute myocardial infarction. J Thromb Haemost. 2011;9:450-6.

11. Smid M, Dielis AWJH, Spronk HMH, Rumley A, van Oerle R, Woodward $M$, et al. Thrombin generation in the Glasgow Myocardial Infarction Study. PLoS One. 2013;8:e66977.

12. Carcaillon $L$, Alhenc-Gelas $M$, Bejot $Y$, Spaft $C$, Ducimetière $P$, Ritchie $K$, et al. Increased thrombin generation is associated with acute ischemic stroke but not with coronary heart disease in the elderly: the Three-City cohort study. Arterioscler Thromb Vasc Biol. 2011;31:1445-51.

13. Panova-Noeva M, Eggebrecht L, Prochaska JH, Wild PS. Potential of Multidimensional, Large-scale Biodatabases to Elucidate Coagulation and Platelet Pathways as an Approach towards Precision Medicine in Thrombotic Disease. Hamostaseologie. 2019;39:152-63.

14. Prandoni P, Bilora F, Marchiori A, Bernardi E, Petrobelli F, Lensing AWA, et al. An association between atherosclerosis and venous thrombosis. N Engl J Med. 2003;348:1435-41.

15. Lowe GDO. Common risk factors for both arterial and venous thrombosis. Br J Haematol. 2008;140:488-95.

16. Schnabel RB, Wilde S, Wild PS, Munzel T, Blankenberg S. Atrial fibrillation: its prevalence and risk factor profile in the German general population. Dtsch Arztebl Int. 2012;109:293-9.

17. Wild PS, Sinning CR, Roth A, Wilde S, Schnabel RB, Lubos E, et al. Distribution and categorization of left ventricular measurements in the general population: results from the population-based Gutenberg Heart Study. Circ Cardiovasc Imaging. 2010;3:604-13.

18. Wild PS, Zeller T, Beutel M, Blettner M, Dugi KA, Lackner KJ, et al. [The Gutenberg Health Study]. Bundesgesundheitsblatt Gesundheitsforschung Gesundheitsschutz. 2012;55:824-9.

19. Loeffen R, Kleinegris M-CF, S T B, Pluijmen PHM, Fens D, van OERLE R, et al. Preanalytic variables of thrombin generation: towards a standard procedure and validation of the method [Internet]. Journal of Thrombosis and Haemostasis. 2012. page 2544-54. Available from: http://dx.doi.org/10.1111/jth.12012

20. van Paridon PCS, Panova-Noeva M, van Oerle R, Schultz A, Hermanns IM, Prochaska JH, et al. Thrombin generation in cardiovascular disease and mortality - results from the Gutenberg Health Study. Haematologica [Internet]. 2019; Available from: http://dx.doi.org/10.3324/haematol.2019.221655

21. Dielis AWJH, A W J, Castoldi E, Spronk HMH, Van Oerle R, Hamulyák K, et al. Coagulation factors and the protein C system as determinants of thrombin generation in a normal population [Internet]. Journal of Thrombosis and Haemostasis. 2007. page 125-31. Available from: http://dx.doi.org/10.1111/j.1538-7836.2007.02824.x

22. Mosesson MW. Fibrinogen and fibrin structure and functions. J Thromb Haemost. 2005;3:1894-904.

23. Spronk HMH, Govers-Riemslag JWP, ten Cate H. The blood coagulation system as a molecular machine. Bioessays. 2003;25:1220-8.

24. Hermanns MI, Grossmann V, Spronk HMH, Schulz A, Jünger C, Laubert-Reh D, et al. Distribution, genetic and cardiovascular determinants of FVIII:C - Data from the population-based Gutenberg Health Study. Int J Cardiol. 2015;187:166-74.

25. Woodward M, Lowe GD, Rumley A, Tunstall-Pedoe H, Philippou H, Lane DA, et al. Epidemiology of coagulation factors, inhibitors and activation markers: The Third Glasgow MONICA Survey. II. Relationships to cardiovascular risk factors and 
prevalent cardiovascular disease. Br J Haematol. 1997;97:785-97.

26. Lowe G, Rumley A. The relevance of coagulation in cardiovascular disease: what do the biomarkers tell us? Thromb Haemost. 2014;112:860-7.

27. Poort SR, Rosendaal FR, Reitsma PH, Bertina RM. A common genetic variation in the 3'-untranslated region of the prothrombin gene is associated with elevated plasma prothrombin levels and an increase in venous thrombosis. Blood. 1996;88:3698-703.

28. Kraaijenhagen RA, in't Anker PS, Koopman MM, Reitsma PH, Prins MH, van den Ende A, et al. High plasma concentration of factor VIIIc is a major risk factor for venous thromboembolism. Thromb Haemost. 2000;83:5-9.

29. van Hylckama Vlieg A, van der Linden IK, Bertina RM, Rosendaal FR. High levels of factor IX increase the risk of venous thrombosis. Blood. 2000;95:3678-82.

30. Ten Cate H. Thrombin generation in clinical conditions. Thromb Res. 2012;129:367-70.

\section{Tables}

Table 1. Study sample characteristics 


\begin{tabular}{|c|c|c|c|}
\hline & $\begin{array}{l}\text { Reference } \\
n=1402\end{array}$ & $\begin{array}{l}\text { Arterial Disease } \\
\mathrm{n}=502\end{array}$ & $\begin{array}{l}\text { Venous Disease } \\
n=195\end{array}$ \\
\hline Sex (females) & $60.5 \%(848)$ & $36.7 \%(184)$ & $63.6 \%(124)$ \\
\hline Age(years) & $49.3 \pm 9.8$ & $63.8 \pm 8.5$ & $61.3 \pm 10.1$ \\
\hline BMI $\left(k g / m^{2}\right)$ & $24.2(22.2 / 26.3)$ & $28.8(25.7 / 32.2)$ & $28.6(25.5 / 31.5)$ \\
\hline \multicolumn{4}{|l|}{ Cardiovascular risk factors } \\
\hline Diabetes & $0 \%(0)$ & $20.1 \%(101)$ & $9.7 \%(19)$ \\
\hline Obesity & $0 \%(0)$ & $41.2 \%(207)$ & $36.9 \%(72)$ \\
\hline Smoking & $22.5 \%(316)$ & $16.2 \%(81)$ & $11.3 \%(22)$ \\
\hline Arterial hypertension & $0 \%(0)$ & $72.5 \%(364)$ & $59.0 \%(115)$ \\
\hline Dyslipidemia & $0 \%(0)$ & $40.1 \%(201)$ & $30.8 \%(60)$ \\
\hline Family history of Ml/Stroke & $31.1 \%(436)$ & $43.6 \%(219)$ & $43.6 \%(85)$ \\
\hline \multicolumn{4}{|l|}{ Comorbidities } \\
\hline CAD & $0 \%(0)$ & $46.5 \%(217)$ & $9.1 \%(17)$ \\
\hline $\mathrm{Ml}$ & $0 \%(0)$ & $30.4 \%(151)$ & $5.2 \%(10)$ \\
\hline Stroke & $0 \%(0)$ & $18.5 \%(92)$ & $6.2 \%(12)$ \\
\hline AF & $0 \%(0)$ & $9.2 \%(45)$ & $6.2 \%(12)$ \\
\hline PAD & $0 \%(0)$ & $40.2 \%(200)$ & $26.6 \%(51)$ \\
\hline $\mathrm{CHF}$ & $0 \%(0)$ & $6.2 \%(31)$ & $6.7 \%(13)$ \\
\hline DVT & $0 \%(0)$ & $14.3 \%(71)$ & $99.0 \%(193)$ \\
\hline PE & $0 \%(0)$ & $1.6 \%(8)$ & $5.7 \%(11)$ \\
\hline \multicolumn{4}{|l|}{ Therapy } \\
\hline Anti-coagulant agents* & $1.8 \%(25)$ & $61.0 \%(305)$ & $35.4 \%(69)$ \\
\hline Oral contraceptive therapy & $12.5 \%(174)$ & $6.4 \%(32)$ & $9.7 \%(19)$ \\
\hline Hormonal replacement therapy & $5.5 \%(77)$ & $5.6 \%(28)$ & $11.3 \%(22)$ \\
\hline
\end{tabular}

Abbreviations: BMI, body mass index; MI, myocardial infarction; AF, atrial fibrillation; PAD, peripheral artery disease; CAD, coronary artery disease; $\mathrm{CHF}$, congestive heart failure; DVT, deep venous thrombosis; PE, pulmonary embolism. * ATC codes: B01AA, B01AB, B01AE, B01AF, B01AX.

Table 2. Parameters of thrombin generation and levels of natural coagulation and anti-coagulant factors in the reference, arterial and venous subsample 


\begin{tabular}{|c|c|c|c|c|c|}
\hline \multirow[t]{3}{*}{ Variab } & \multicolumn{5}{|l|}{ Subsample } \\
\hline & $\begin{array}{l}\text { Reference } \\
(n=1402)\end{array}$ & $\begin{array}{l}\text { Arterial Disease } \\
(n=502)\end{array}$ & \multirow{2}{*}{$\begin{array}{l}\mathrm{p} \text {-value } \\
\text { arterial disease vs. } \\
\text { reference }\end{array}$} & $\begin{array}{l}\text { Venous Disease } \\
(n=195)\end{array}$ & \multirow{2}{*}{$\begin{array}{l}\text { p-value } \\
\text { venous disease vs. } \\
\text { reference }\end{array}$} \\
\hline & Mean $\pm S D$ & Mean $\pm S D$ & & Mean $\pm S D$ & \\
\hline $\begin{array}{l}\text { Lag Time } \\
\text { [min] }\end{array}$ & $4.94 \pm 1.03$ & $6.56 \pm 3.71$ & $<0.0001$ & $6.50 \pm 3.95$ & $<0.0001$ \\
\hline ETP [nM.min] & $1105.0 \pm 237.4$ & $1045.0 \pm 360.8$ & 0.00056 & $1048.5 \pm 423.3$ & 0.070 \\
\hline $\begin{array}{l}\text { Peak Height } \\
\text { [nM] }\end{array}$ & $118.37 \pm 54.81$ & $113.09 \pm 55.36$ & 0.067 & $113.50 \pm 60.32$ & 0.29 \\
\hline Factor II [\%] & $116.9 \pm 17.6$ & $108.7 \pm 28.9$ & $<0.0001$ & $104.8 \pm 32.7$ & $<0.0001$ \\
\hline Factor V [\%] & $116.6 \pm 18.5$ & $118.9 \pm 19.9$ & 0.024 & $118.4 \pm 22.0$ & 0.29 \\
\hline Factor VII [\%] & $111.1 \pm 21.6$ & $108.3 \pm 31.2$ & 0.056 & $107.2 \pm 34.8$ & 0.12 \\
\hline Factor VIII [\%] & $115.3 \pm 33.1$ & $136.3 \pm 40.2$ & $<0.0001$ & $140.1 \pm 46.5$ & $<0.0001$ \\
\hline Factor IX [\%] & $106.3 \pm 14.4$ & $110.9 \pm 21.7$ & $<0.0001$ & $107.4 \pm 24.3$ & 0.53 \\
\hline Factor X [\%] & $113.10 \pm 19.09$ & $105.59 \pm 33.53$ & $<0.0001$ & $103.87 \pm 38.95$ & 0.0013 \\
\hline Factor XI [\%] & $106.8 \pm 18.2$ & $110.2 \pm 19.8$ & 0.00090 & $112.6 \pm 19.4$ & $<0.0001$ \\
\hline Factor XII [\%] & $105.6 \pm 24.3$ & $102.1 \pm 24.9$ & 0.0071 & $105.5 \pm 24.7$ & 0.98 \\
\hline vWF [\%] & $103.1 \pm 35.5$ & $127.7 \pm 45.0$ & $<0.0001$ & $127.7 \pm 48.3$ & $<0.0001$ \\
\hline Protein C [\%] & $113.3 \pm 17.2$ & $111.3 \pm 26.1$ & 0.097 & $110.2 \pm 28.3$ & 0.13 \\
\hline Protein S [\%] & $95.1 \pm 16.4$ & $100.3 \pm 24.1$ & $<0.0001$ & $93.4 \pm 24.7$ & 0.34 \\
\hline $\begin{array}{l}\text { Antithrombin } \\
{[\%]}\end{array}$ & $102.8 \pm 9.8$ & $98.1 \pm 11.9$ & $<0.0001$ & $100.8 \pm 10.7$ & 0.014 \\
\hline $\begin{array}{l}\text { TFPI Activity } \\
{[\mathrm{U} / \mathrm{mL}]}\end{array}$ & $1.57 \pm 0.53$ & $1.63 \pm 0.57$ & 0.040 & $1.64 \pm 0.52$ & 0.084 \\
\hline $\begin{array}{l}\text { Fibrinogen } \\
\text { [mg/dL] }\end{array}$ & $331 \pm 66$ & $395 \pm 95$ & $<0.0001$ & $391 \pm 95$ & $<0.0001$ \\
\hline
\end{tabular}

Presented are thrombin generation parameters and coagulation factors in the reference, arterial disease and venous disease subsample. Abbreviations: SD, standard deviation; vWF, Von Willebrand Factor; TFPI, Tissue Factor Pathway Inhibitor.

Table 3. Biochemical determinants of the TG parameters in the reference subsample and arterial and venous subsample 
Subsamples: Reference

$\log ($ Lag time $\quad$ Beta per SD $(95 \% \mathrm{Cl})$

$1 \mathrm{pM}$ [min])

Factor II [\%] $\quad$ ), $)^{0175(0.00972 / 0.0253<0.0001}$ Factor $\mathrm{V}[\%] \quad$ ) $\quad$, $0227(0.0149 / 0.0305<0.0001$

p value
Arterial disease

$\begin{array}{ll}\text { Factor VII [\%] } & -0,0175 \\ & (-0.0254 /-0.00972)\end{array}$

Protein S [\%]

Antithrombin
$[\%]$

TFPI Activity

Fibrinogen $\quad 0,0408(0.0330 / 0.0486$ $[\mathrm{mg} / \mathrm{dL}] \quad$ )

Factor XII [\%]

$-0,0112$

$(-0.0191 /-0.00332)$

$\begin{array}{ll}\text { Protein C [\%] } & 0,0094 \\ & (0.00148 / 0.0173)\end{array}$

$\begin{array}{ll}\text { Factor XI [\%] } & 0,00737 \\ & (-0.000621 / 0.0154)\end{array}$

Factor X [\%] $\quad 0,00335$

$(-0.00445 / 0.0112)$

Factor IX [\%]

0,00253

$(-0.00542 / 0.0105)$

vWF $[\%]$

0,00121
$(-0.00681 / 0.00923)$

Factor VIII

[\%]

0,000547

$(-0.00746 / 0.00855)$

$<0.0001 \quad-0,156$

0,0312

0,0255

)

0,77

$-0,0127$

)

0,89

$-0,00312$

$(-0.0320 / 0.0257$
$<0.0001$

Beta per SD $(95 \% \quad p$ value

Cl)

$-0,18$
$(-0.203 /-0.157)$

$-0,0712$

$(-0.0981 /-0.0444$

$-0,168$

$(-0.191 /-0.144)$

$(-0.180 /-0.132)$

$<0.0001 \quad-0,181$

$(-0.204 /-0.159)$

$<0.0001 \quad-0,153$

$(-0.178 /-0.129)$

$<0.0001$

$-0,124$

$(-0.149 /-0.0986)$

0,0053

0,151

$(0.126 / 0.175)$

0,02

0,0527

$(0.0250 / 0.0804)$

0,071

0,0333

$(0.00536 / 0.0612$

)

$<0.0001$

0,019
Venous disease

Beta per SD $(95 \%$ p value

Cl)

$<0.0001 \quad-0,227(-0.264 /-0.190 \quad<0.0001$

$-0,201$

$(-0.240 /-0.162)$

$<0.0001$

$<0.0001$

$(-0.233 /-0.158)$

$<0.0001 \quad-0,217$
$\quad(-0.253 /-0.180)$

$<0.0001$

$<0.0001 \quad-0,205$

$(-0.243 /-0.166)$

$<0.0001$

$<0.0001 \quad-0,169$

$(-0.208 /-0.129)$

$<0.0001$

$<0.0001 \quad 0,148(0.105 / 0.190 \quad<0.0001$

$<0.0001 \quad-0,081$

$(-0.126 /-0.0356)$

0,00047

$0,00019 \quad-0,041$

$(-0.0883 / 0.00620)$

0,089

0,0254

$(-0.0218 / 0.0726)$

0,29

$(0.00340 / 0.0591$

0,028

0,0246

$(-0.0214 / 0.0706)$

0,29

$(-0.00218 / 0.0531$

0,071

0,0195

$(-0.0280 / 0.0670)$

0,42

$(-0.0405 / 0.0152$

0,37

0,0166

$(-0.0294 / 0.0627)$

0,48

0,83

)
Subsample: Reference

ETP 1pM

[nM.min]

Factor II [\%] 69,3(57.5/81.0)

Factor VII [\%] 55,2 (43.2/67.2)

Factor VIII $\quad 55,6(43.4 / 67.8)$

[\%]

Factor IX [\%] $\quad 69,2(57.3 / 81.1)$

Factor $X[\%] \quad 55,9(44.1 / 67.8)$

\section{Arterial disease}

p value

Beta per SD $(95 \% \quad$ p value

Cl)

$<0.0001 \quad 225(200 / 250)$

$<0.0001 \quad 111(80.8 / 142)$

$<0.0001 \quad 184(156 / 212)$

$<0.0001205(178 / 231)$

$<0.0001221(196 / 247)$

Page 13/14

\section{Venous disease}

Beta per SD ( $95 \%$

$\mathrm{Cl})$

p value

$<0.0001$

$<0.0001$

$<0.0001$

$<0.0001$

$<0.0001$ 


\begin{tabular}{|c|c|c|c|c|c|c|}
\hline Factor XI [\%] & $40,2(27.9 / 52.6)$ & $<0.0001$ & $174(145 / 203)$ & $<0.0001$ & $208(155 / 261)$ & $<0.0001$ \\
\hline Factor XII [\%] & $54,2(42.1 / 66.2)$ & $<0.0001$ & $165(137 / 193)$ & $<0.0001$ & $170(117 / 222)$ & $<0.0001$ \\
\hline vWF [\%] & 45,5 (33.1/57.8) & $<0.0001$ & )$^{-78,6(-110 /-46.8}$ & $<0.0001$ & $-123(-178 /-67.1)$ & $<0.0001$ \\
\hline Protein C [\%] & $25(12.6 / 37.3)$ & $<0.0001$ & )$^{-69,5(-101 /-38.2}$ & $<0.0001$ & $71,9(12.9 / 131)$ & 0,017 \\
\hline $\begin{array}{l}\text { Antithrombin } \\
{[\%]}\end{array}$ & $-40,4(-52.5 /-28.3)$ & $<0.0001$ & $57(24.8 / 89.2)$ & 0,00052 & $66(6.74 / 125)$ & 0,029 \\
\hline $\begin{array}{l}\text { Fibrinogen } \\
{[\mathrm{mg} / \mathrm{dL}]}\end{array}$ & $52,6(40.3 / 65.0)$ & $<0.0001$ & $49,9(16.8 / 83.0)$ & 0,0031 & $56,6(-2.58 / 116)$ & 0,061 \\
\hline $\begin{array}{l}\text { TFPI Activity } \\
{[\mathrm{U} / \mathrm{mL}]}\end{array}$ & $-19(-31.7 /-6.32)$ & 0,0033 & $43,4(11.0 / 75.7)$ & 0,0085 & $-52,2(-110 / 5.90)$ & 0,078 \\
\hline Factor V [\%] & $6,96(-5.47 / 19.4)$ & 0,27 & 42,8 (10.8/74.9) & 0,0089 & $-48,7(-106 / 9.06)$ & 0,098 \\
\hline Protein S [\%] & 0,0931 (-13.1/13.3) & 0,99 & )$^{-16,2(-48.3 / 15.9}$ & 0,32 & $37,1(-21.7 / 95.8)$ & 0,22 \\
\hline Subsamples: & Reference & & Arterial disease & & Venous disease & \\
\hline $\begin{array}{l}\text { Peak height } \\
\text { 1pM [nM] }\end{array}$ & Beta per SD $(95 \% \mathrm{Cl})$ & $p$ value & $\begin{array}{l}\text { Beta per SD (95\% } \\
\text { Cl) }\end{array}$ & p value & $\begin{array}{l}\text { Beta (per SD) (95\% } \\
\text { Cl) }\end{array}$ & p value \\
\hline Factor II [\%] & 10,2 (7.38/13.0 ) & $<0.0001$ & $22(17.5 / 26.5)$ & $<0.0001$ & $31,2(23.4 / 39.0)$ & $<0.0001$ \\
\hline Factor VII [\%] & $17,6(14.9 / 20.4)$ & $<0.0001$ & $10,4(5.60 / 15.2)$ & $<0.0001$ & $24,4(16.2 / 32.6)$ & $<0.0001$ \\
\hline $\begin{array}{l}\text { Factor VIII } \\
{[\%]}\end{array}$ & 16,7 (13.9/19.5) & $<0.0001$ & $18(13.3 / 22.6)$ & $<0.0001$ & 22,8 (14.7/30.9) & $<0.0001$ \\
\hline Factor IX [\%] & $8,28(5.48 / 11.1)$ & $<0.0001$ & $14,9(10.1 / 19.7)$ & $<0.0001$ & $32,9(25.7 / 40.1)$ & $<0.0001$ \\
\hline Factor X [\%] & $8,53(5.66 / 11.4)$ & $<0.0001$ & $23(18.6 / 27.4)$ & $<0.0001$ & 28,6 (20.8/36.3) & $<0.0001$ \\
\hline vWF [\%] & 14,3 (11.6/17.1) & $<0.0001$ & $22,9(18.4 / 27.3)$ & $<0.0001$ & $19,1(10.8 / 27.4)$ & $<0.0001$ \\
\hline Protein C [\%] & 15,5 (12.7/18.3 ) & $<0.0001$ & 15,3 (10.4/20.1) & $<0.0001$ & 23,8 (15.6/32.0) & $<0.0001$ \\
\hline Protein S [\%] & $-7,93(-10.8 /-5.11)$ & $<0.0001$ & $16,5(11.8 / 21.2)$ & $<0.0001$ & $17,5(9.46 / 25.6)$ & $<0.0001$ \\
\hline $\begin{array}{l}\text { TFPI Activity } \\
{[\mathrm{U} / \mathrm{mL}]}\end{array}$ & 8,18 (5.27/11.1) & $<0.0001$ & $16,2(11.6 / 20.9)$ & $<0.0001$ & $-11(-19.4 /-2.55)$ & 0,011 \\
\hline Factor V [\%] & $5,6(2.77 / 8.44)$ & 0,00011 & 7,66 (2.77/12.6 ) & 0,0021 & $10,6(2.08 / 19.0)$ & 0,015 \\
\hline Factor XI [\%] & $-5,8(-8.73 /-2.87)$ & 0,00011 & )$^{-7,58(-12.4 /-2.75}$ & 0,0021 & $9,92(1.29 / 18.6)$ & 0,024 \\
\hline Factor XII [\%] & $3,79(0.916 / 6.67)$ & 0,0098 & )$^{-6,55(-11.5 /-1.60}$ & 0,0094 & $8,98(0.470 / 17.5)$ & 0,039 \\
\hline $\begin{array}{l}\text { Antithrombin } \\
{[\%]}\end{array}$ & $-3,7(-6.75 /-0.652)$ & 0,017 & )$^{4,99(-0.101 / 10.1}$ & 0,055 & $-7,86(-16.3 / 0.545)$ & 0,067 \\
\hline $\begin{array}{l}\text { Fibrinogen } \\
{[\mathrm{mg} / \mathrm{dL}]}\end{array}$ & $-3,35(-6.23 /-0.476)$ & 0,022 & )$^{-2,99(-7.91 / 1.94}$ & 0,23 & $-5,19(-13.8 / 3.42)$ & 0,24 \\
\hline
\end{tabular}

The multiple linear regression models were adjusted for age, sex and medication. Abbreviations: vWF, Von Willebrand Factor; TFPI, Tissue Factor Pathway Inhibitor. * ATC codes: B01AA, B01AB, B01AE, B01AF, B01AX. 